\title{
Association of erectile dysfunction and urolithiasis
}

\author{
Alper Otunctemur ${ }^{1}$, Emin Ozbek ${ }^{2}$, Suleyman Sami Cakir ${ }^{3}$, Murat Dursun ${ }^{4}$, Emre Can Polat ${ }^{5}$, \\ Levent Ozcan ${ }^{6}$, Osman Kose ${ }^{2}$, Huseyin Besiroglu ${ }^{1}$ \\ ${ }^{1}$ Okmeydani Training and Research Hospital, Department of Urology, Istanbul, Turkey; \\ ${ }^{2}$ Katip Celebi University, Ataturk Training and Research Hospital, Department of Urology, Izmir, Turkey; \\ ${ }^{3}$ Bayburt State Hospital, Department of Urology, Bayburt, Turkey; \\ ${ }^{4}$ Bahcelievler State Hospital, Department of Urology, Istanbul, Turkey; \\ 5 İstanbul Medipol University, Faculty of Medicine, Department of Urology, Istanbul, Turkey; \\ ${ }^{6}$ Derince Training and Research Hospital, Department of Urology, Kocaeli, Turkey.
}

\begin{abstract}
Summary Objectives: In recent years, it has been shown that there is association between metabolic syndrome and urinary stone disease. Stone disease and erectile dysfunction (ED) are considered as systemic diseases which are associated with hormonal and metabolic disorders. Therefore we investigated the relationship between ED and urinary tract calculi. Material and methods: 98 male patients with urolithiasis and 59 randomly selected male patients without stone disease were included in the study. Serum testosterone (T) levels were measured and International Index of Erectile Function (IIEF)-15 questionnaire forms were used to assess ED.

Results: The prevalence of ED was found 29\% (29 patients) in the urolithiasis group. Sixty-nine patients (71\%) had no ED; 16 (16.3\%) had mild, 5 (5.1\%) had moderate and $8(8.2 \%)$ had severe ED. None of the patients in the control group had severe or modarete ED, six patients (10.2\%) had mild ED. Serum T levels were detected at the level of biochemical hypogonadism on 13 patients with stones $(13.3 \%)$ and $T$ levels were detected at the lower limit in $18(18.3 \%)$ patients.

Conclusion: In our study we have shown that ED and low $T$ levels are significantly associated with urolithiasis. We propose that the patients with urolitiasis should be evaluated for ED and hypogonadism.
\end{abstract}

KEY WORDS: Urolithiasis; Erectile dysfunction; Metabolic syndrome; Testosterone; Hypogonadism; IIEF.

Submitted 29 June 2014; Accepted 1 August 2014

\section{INTRODUCTION}

Erectile dysfunction (1) is defined as the consistent inability to obtain and/or maintain a penile erection which is sufficient to permit satisfactory sexual intercourse (2). It is estimated that more than 150 million men worldwide have ED and the global prevalence is increasing along with aging population trends $(3,4)$. ED has been associated with signs of generalized arterial disease, as it frequently coexists with diseases with a high component of endothelial dysfunction, such as coronary artery disease, idiopathic systemic arterial hypertension, atherosclerosis and end-stage chronic kidney disease. ED is also associated with cardiovascular disease risk factors, such as diabetes mellitus, dyslipidemia, and smoking (1, 5-7). Low testosterone levels are significantly associated with prevalence of MetS $(8,9)$.

Obesity and components of metabolic syndrome have been associated with nephrolithiasis, and several studies have suggested that metabolic syndrome is linked directly to the formation of urolithiasis (10-12). The higher prevalence of stone disease in patients with metabolic syndrome suggests that insulin resistance might have a role in the pathophysiology of nephrolithiasis $(13,14)$. Although, stone disease and ED are defined as systemic diseases which are associated with hormonal and metabolic disorders, there are few studies on the association of ED and stone disease. We estimated the association of ED with urolithiasis and testosterone levels in the patients who were admitted to our clinic.

\section{MATERIAL AND METHODS}

This study assessed the prevalence rate of ED in men with urolithiasis. We identified as the study group 98 male patients with urolithiasis who had experienced spontaneous stone passage or surgery for urolithiasis (percutaneous nephrolithotomy, ureterorenoscopy) or whose stones were radiologically (ultrasonography, computed tomography or intravenous urography) visible at the onset of clinical symptoms and 59 randomly selected male patients as the controls. Mean age of the study group was $48.49 \pm 10.87 \neq$ years (range: $28-67$ ) and mean age of controls was $47.28 \pm 8.62$ years (range:31-64). There was no significant difference between mean age of patients and control group. The study population for this case-control study consisted of patients who were admitted to our clinic. Subjects having severe cardiovascular disease, endocrine or neurological disease were excluded from study. Serum testosterone $(\mathrm{T})$ levels were evaluated on blood samples taken between 08.00 and 10.00 in the fasting state. Serum T was measured using enzymatic methods with an autoanalyzer. International Index of Erectile Function (IIEF)-15 questionnaire which was validated for use in Turkey was 
applied to all patients. According to the IIEF-15 questionnaire, we evulated scores between 6 and 10 as severe dysfunction, between 11 and 18 as moderate dysfunction, between 19 and 24 as mild dysfunction and between 25-30 no dysfunction. Low testosterone level was considered when $<110 \mathrm{ng} / \mathrm{dl}$ whereas levels from 110 to $285 \mathrm{ng} / \mathrm{dl}$ were considered as the lower limit of testosterone level. Local ethics committee approval had been obtained before the commence of the study.

\section{Statistics}

Analyses were completed using Chi-square tests. Odds ratios (OR) were calculated. Statistical determinations were within the 95\% confidence interval (CI). All p values were two-tailed, and p 0.05 was considered statistically significant. The data were analyzed with an SPSSTM (SPSS version 13.0, Chicago, IL) statistical software package.

\section{RESULTS}

The prevalence of ED was found 29\% (29 patients) in the urolithiasis group. Sixty-nine patients (71\%) had no ED, $16(16.3 \%)$ mild ED, 5 (5.1\%) moderate ED and 8 $(8.2 \%)$ severe ED. None of the patients in the control group had severe or modarete ED and six patients (10.2\%) had mild ED ( $p=0.0084)$. A significantly higher proportion of ED was found among patients with urolithiasis compared with controls (Table 1).

Serum T levels were detected at the level of biochemical hypogonadism on 13 (13.3\%) of patients with stones and $\mathrm{T}$ levels were detected at the lower limit in other 18 (18.3\%) patients. Biochemical hypogonadism was never observed in the controls whereas $\mathrm{T}$ levels at the lower range were detected in only 8 patients $(p=0.018)$ (Table 2). Serum T levels were dedected at the lower limit in 3 patients with mild ED and at the level of biochemical hypogonadism in 7 patients with severe ED.

\section{Conclusions}

In our study we have shown that ED and low $\mathrm{T}$ levels are significantly associated with urolithiasis. We suggest that the patients with urolitiasis should be evaluated for ED

\section{Table 1.}

IIEF-15: International Index of Erectile Function.

\begin{tabular}{|l|c|c|c|c|}
\hline & $\begin{array}{c}\text { IIEF-5 } \\
\text { severe ED } \\
\text { (6-10) }\end{array}$ & $\begin{array}{c}\text { IIEF-5 } \\
\text { moderate ED } \\
\text { (11-18) }\end{array}$ & $\begin{array}{c}\text { IIEF-15 } \\
\text { mild ED } \\
\text { (19-24) }\end{array}$ & $\begin{array}{c}\text { IIEF-15 } \\
\text { No ED }\end{array}$ \\
\hline Subject with stone & $8(9.2 \%)$ & $5(5.1 \%)$ & $16(16.3 \%)$ & $69(71 \%)$ \\
\hline Subject without stone & - & - & $6(8.2 \%)$ & $53(89 \%)$ \\
\hline & & & & $\mathrm{P} 0.0084$ \\
\hline
\end{tabular}

Table 2.

STL: Serum Testosterone Level.

\begin{tabular}{|l|c|c|}
\hline & STL < $\mathbf{1 1 0} \mathbf{n g} / \mathbf{d L}$ & STL between $\mathbf{1 1 0}$ to $\mathbf{2 8 5} \mathbf{n g} / \mathbf{d L}$ \\
\hline Subject with stone & $13(13.3 \%)$ & $18(18.3 \%)$ \\
\hline Subject without stone & - & $8(13.5 \%)$ \\
\hline & & $\mathrm{P}=0.018$ \\
\hline
\end{tabular}

and hypogonadism, and consequently life-style arrangements are to be planned for treatment.

\section{References}

1. Mesquita JF, et al. Prevalence of erectile dysfunction in chronic renal disease patients on conservative treatment. Clinics (Sao Paulo) 2012; 67:181-3

2. Santos T, Drummond M, Botelho F Erectile dysfunction in obstructive sleep apnea syndrome - Prevalence and determinants. Rev Port Pneumol. 2012; 18:64-71.

3. Lewis RW, et al. Definitions/epidemiology/risk factors for sexual dysfunction. J Sex Med. 2010; 7:1598-607.

4. Ayta IA, McKinlay JB, Krane RJ The likely worldwide increase in erectile dysfunction between 1995 and 2025 and some possible policy consequences. BJU Int. 1999; 84:50-6.

5. Vlachopoulos C, et al. Arterial function and intima-media thickness in hypertensive patients with erectile dysfunction. J Hypertens. 2008; 26:1829-36.

6. Koca O, et al Vasculogenic erectile dysfunction and metabolic syndrome. J Sex Med. 2010; 7:3997-4002.

7. Lee YC, et al. The potential impact of metabolic syndrome on erectile dysfunction in aging Taiwanese males. J Sex Med. 2010; 7:3127-34.

8. Kupelian $V$, et al. Inverse association of testosterone and the metabolic syndrome in men is consistent across race and ethnic groups. $J$ Clin Endocrinol Metab. 2008; 93:3403-10.

9. Goncharov NP, et al. Three definitions of metabolic syndrome applied to a sample of young obese men and their relation with plasma testosterone. Aging Male 2008; 11:118-22.

10. Taylor EN, Stampfer MJ, Curhan GC Obesity, weight gain, and the risk of kidney stones. JAMA 2005; 293:455-62.

11. Taylor EN, Stampfer MJ, Curhan GC. Diabetes mellitus and the risk of nephrolithiasis. Kidney Int. 2005; 68:1230-5.

12. Curhan GC. et al. Body size and risk of kidney stones. J Am Soc Nephrol. 1998; 9:1645-52.

13. West B, et al. Metabolic syndrome and self-reported history of kidney stones: the National Health and Nutrition Examination Survey (NHANES III) 1988-1994. Am J Kidney Dis. 2008; 51:741-7

14. Obligado SH, Goldfarb DS The association of nephrolithiasis with hypertension and obesity: a review. Am J Hypertens. 2008; 21:257-64.

\section{Correspondence}

Alper Otunctemur, MD

alperotunctemur@yahoo.com

Huseyin Besiroglu, MD

Okmeydani Training and Research Hospital, Department of Urology, 34384, Sisli, Istanbul, Turkey

Emin Ozbek, MD

Osman Kose, MD

Katip Celebi University, Ataturk Training and Research Hospital, Department of Urology, Izmir, Turkey

Suleyman Sami Cakir, MD

Bayburt State Hospital, Department of Urology, Bayburt, Turkey

Murat Dursun, MD

Bahcelievler State Hospital, Department of Urology, Istanbul, Turkey

Emre Can Polat, MD

İstanbul Medipol University, Faculty of Medicine, Department of Urology, Istanbul, Turkey

Levent Ozcan, MD

Derince Training and Research Hospital, Department of Urology, Kocaeli, Turkey 